\title{
Child health care nurses' strategies in meeting with parents who are hesitant to child vaccinations
}

\author{
Julia Dahlqvist, Josefin Stalefors, Sandra Pennbrant \\ Division of Nursing, Department of Nursing, Health and Culture, University West, Trollhättan, Sweden \\ Correspondence: Sandra Pennbrant. Address: Division of Nursing, University West, 46186 Trollhättan, Sweden. \\ Email: sandra.pennbrant@hv.se
}

Received: June 26, 2014

Accepted: August 18, 2014

Online Published: August 25, 2014

DOI : $10.5430 /$ cns.v2n4p47

URL: http://dx.doi.org/10.5430/cns.v2n4p47

\section{Abstract}

Aim: The aim of this study was to describe how nurses in child health centres deal with parents who are hesitant to child vaccinations.

Method: A study with a qualitative approach that was based on 12 semi-structured interviews. The informants were nurses working in child health centres in the Västra Götaland region. The interviews were analysed using qualitative content analysis.

Results: The results identified six strategies for dealing with vaccine-hesitant parents: 1) using the family's resources and knowledge to create a trusting relationship; 2) meetings with the same nurse; 3) open dialogue and active listening; 4) regular meetings between nurse and paediatrician; 5) nurse training on new vaccines and vaccination programme; and 6) nurse training on parents' use of publicly available information.

Conclusion: Nurses should get to know the vaccine-hesitant parents, by listening to them and understanding their point of view. Thereby, nurses establish a good relationship, inspire trust and actively involve the parents in the decision-making concerning the vaccination of their child. Nurses should not make vaccine-hesitant parents feel guilty about not wanting to vaccinate their child.

\section{Key words}

Child health nurse, Family-centred care, Qualitative content analysis, Strategy, Vaccine-hesitant parent

\section{I ntroduction}

In Sweden all families with children are offered to participate in the childhood vaccination programme. Most of the diseases covered by this programme have virtually disappeared due to good vaccination coverage, although they have not been eradicated ${ }^{[1]}$. This has created a situation where the side effects of the vaccines are more visible than the potential effects and damages of the diseases. Research has been made on why parents decide whether or not to vaccinate their child ${ }^{[2-6]}$. However, there is no research on how nurses deal with parents who are hesitant to child vaccinations or what strategies nurses use in the meeting with such parents. The aim of this study is to describe how nurses in child health centres deal with parents who are hesitant to child vaccinations. 


\subsection{Research on concerns and hesitations about child vaccinations}

Research shows that the following factors can influence parents in their decision whether or not to vaccinate: their understanding of the risks and advantages of vaccines, information from various media and other sources about vaccination safety, trust in the advice provided by health care personnel, and the importance of the individual choice in relation the vaccination recommendations issued by authorities ${ }^{[7]}$. The parents' social network with relatives, friends, colleagues and health care personnel can also influence their attitude to child vaccinations ${ }^{[8]}$.

A common reason for hesitation towards child vaccination is the parents' concerns about side effects and the effects of the vaccine on the child's body and immune defence system. They believe that the side effects of the vaccines can cause severe diseases. Some parents also see a danger in disturbing the natural development of the immunity against various diseases. They believe that the individual becomes stronger by experiencing childhood diseases naturally instead of by injecting substances into the body ${ }^{[9]}$. Many vaccine-hesitant parents are convinced that something in the vaccine is poisoning their child ${ }^{[10]}$.

In a situation where the diseases included in the childhood vaccination programme occur only rarely among the public the question of the rationale for vaccinations arises and can lead to hesitation ${ }^{[11]}$. Not having seen or experienced the immediate effects of the childhood diseases makes it difficult for parents to see the gains of vaccination ${ }^{[12]}$. It is a question of weighing advantages and disadvantages. For a given vaccine such an assessment can vary over time; as the disease becomes less common our acceptance of disadvantages decreases ${ }^{[13]}$.

In today's connected society parents investigate and gather information on their own. Instead of inspiring a greater sense of security the larger volume of information can inspire doubt ${ }^{[14]}$. It is difficult for parents to determine which sources are reliable as many vaccine-critical Internet sites present themselves are sources of scientific information and play on the parents' emotions ${ }^{[10]}$. Mass media are significant sources of health care information and can also make parents doubtful and hesitant about child vaccination ${ }^{[7,11]}$. In a study by Wakefield et al. ${ }^{[15]}$ it is claimed that the vaccination against measles, mumps and rubella (MMR) contains poisons that can lead to vaccine-induced autism. Despite the article having been retracted many parents remain doubtful and worried. Subsequent studies have attempted to find a link between the MMR vaccine and autism ${ }^{[16]}$. When reports of this appear anywhere in the world fear and distrust towards vaccines are generated, making parents confused and more prone to decide against vaccinating their child ${ }^{[2]}$. Articles about the risks of vaccination are five times more common than articles about the advantages of vaccination ${ }^{[17]}$.

\subsection{Encouraging a feeling of trust and participation among parents who are hesitant to child vaccinations}

Child health care efforts should be based on a public-health perspective and embrace a holistic attitude. The nurse is expected to promote the parents' belief in themselves and their problem-solving ability ${ }^{[18]}$. Major factors for empowering parents in their decision-making and involving them are a bilateral and respectful relationship with the nurse, a well-working dialogue, and good accessibility ${ }^{[19]}$. This can be promoted by the nurse adopting a family-centred attitude and using the family's resources and knowledge ${ }^{[20]}$.

By adopting a family-centred attitude the nurse makes the parents feel trust, thus promoting the development of a good relationship between the parties ${ }^{[11,19]}$. For the sake of this trustful relationship, it is important the parents and child meet with the same nurse as far as possible ${ }^{[21]}$. The trust between the family and the nurse is mutual and both parties can rely on each other. Parents seek respect and knowledge in the cooperation with the nurse ${ }^{[22]}$. The nurse must be good at listening and be attentive to the family's needs. By listening with an open mind, the nurse can identify individual needs and wishes and identify the family's resources ${ }^{[23]}$. Satisfaction with the vaccination appointment can lead to significant domino effects and increase the likelihood of parents returning for subsequent vaccine doses and completing the childhood vaccination programme. Nurses who treat parents as individuals, spend time with them, encourage dialogue and listen to questions find it easier to create a good and lasting relationship ${ }^{[24]}$. 
Nurses are responsible for providing information about vaccines and for promoting them to parents ${ }^{[25]}$. Parents who decide to not vaccinate their child should be treated with the same respect as parents who decide to vaccinate. By having a family-centred attitude towards the parents, the latter are given time and space to express their views on vaccination in a manner suited to the specific situation ${ }^{[20]}$. Good communication between the nurse and the parents is therefore one of the key factors for maintaining the latter's trust in vaccination ${ }^{[24]}$.

Childhood diseases entail much larger risks than vaccines ${ }^{[1,26]}$. Past research describes how parents who are hesitant to child vaccinations experience the meeting with the nurse and why parents decide whether or not to vaccinate their child. However, there are no specific descriptions of how nurses deal with vaccine-hesitant parents or what strategies the nurses implement. This study focuses on how child health nurses deal with parents who are hesitant to child vaccinations.

\subsection{Aim}

The aim was to describe how nurses in child health centres deal with parents who are hesitant to child vaccinations.

\section{Method}

The study was empirical with a qualitative approach and a descriptive design. The qualitative approach is used to understand a person's subjective experience of, for instance, quality of life, experiences, perceptions, actions or ways of reasoning ${ }^{[27]}$.

\subsection{Selection criteria and respondents}

Nurses working in strategically selected child health centres were eligible to be respondents in the study. Strategic selection is an approach providing a comprehensive view and general conclusions based on small populations ${ }^{\text {[27] }}$. To achieve the widest possible variation in the results and to achieve the study's aim, the strategic selection was made among child health centres located in seven municipalities in the Västra Götaland Region in western Sweden. Countryside and city areas, as well as areas presenting varying socioeconomic characteristics, were represented.

The nurses were contacted by phone and given information about the study. Interview meetings were arranged. A total of 12 nurses/respondents, all women, were interviewed. The nurses had all completed a postgraduate programme in specialist nursing/primary health care (75 higher education credits), were aged 31 to 61 years and had worked in child health centres for 2 to 33 years.

\subsection{Data collection}

Data collection was carried out by two researchers (JD, JS). Twelve selected child health nurses were interviewed individually in January and February 2014. The interviews were carried out at the nurse's place of work, in a setting ensuring no disturbance or interruption, were taped, and lasted 30 to 45 minutes. An interview began by encouraging the nurse to describe her background freely, then semi-structured questions were put to her and follow-up questions asked as needed. This approach allowed the nurses to determine the structure of their answers. Initially, two individual test interviews were made by separate researchers (JD, JS) to validate the interview technique. These interviews were deemed successful and were included in the study. The taped interviews were transcribed for the subsequent analysis.

\subsection{Analysis}

Graneheim and Lundman's ${ }^{[28]}$ description of content analysis was used as the analysis method. Qualitative content analysis is based on analysis of the content to achieve understanding and knowledge about people's experiences and descriptions of a given phenomenon. The transcribed interviews were read several times by the researchers to obtain an initial impression of the data and ask "what are the texts saying?” about how the nurses deal with the parents. Meaning units were identified and condensed to shorten the text, while remaining true to its original content. The meaning units 
were marked, coded and grouped according to their content. The codes described the content of their respective meaning units at a more abstract level than the condensate. The groups were compared in terms of differences and similarities. This process led to the identification of categories and their subcategories. All the interview texts were repeatedly reread to confirm that the categories and subcategories provided a complete and reliable representation of the texts. In the results section quotations from the interviews are presented to offer the reader an opportunity to determine the reliability of the interpretations of the nurses' statements.

The data from the twelve individual interviews were analysed separately by all three researchers (JD, JS and SP) and were subsequently discussed among them to draw conclusions.

\subsection{Ethical considerations}

The study adhered to the relevant ethical recommendations of the Swedish Research Council ${ }^{[29]}$. Written information on the study's aim and use, and on the right to interrupt participation at any point, was provided to the responding nurses and their oral and written consent was obtained prior to commencing the study. For the nurses' protection, a coding system was used to anonymise their names and places of work.

\section{Results}

The results are presented in the form of strategies used by child health nurses when dealing with parents who are hesitant to child vaccinations. The strategies are presented in the form of categories and their subcategories in Table 1.

Table 1. Overview of the strategies of child health nurses when dealing with parents who are hesitant to child vaccinations

\begin{tabular}{ll}
\hline Category & Subcategory \\
\hline Being supportive & - Being understanding \\
& - Creating a relationship \\
& - Inspiring trust \\
Being a discussion partner & - Getting to know \\
Providing knowledge & - Encouraging participation \\
& - Providing information \\
& - Providing advice \\
\hline
\end{tabular}

\subsection{Being supportive}

The nurses stated that it is necessary to be supportive in the meeting with parents who are hesitant to child vaccinations. The support entails being understanding, creating a relationship, and inspiring trust. These strategies include respecting, accepting and supporting the parents in their decision.

\subsubsection{Being understanding}

The nurses described the importance of being understanding towards vaccine-hesitant parents and of not questioning or making demands on them. With their demeanour the nurses show that they listen to and respect the parents' opinions and decision.

"In my work I have always been very careful to respect the parents' decision irrespective of whether or not they want to vaccinate” (I 3). 
It is difficult to reach the parents if the nurses make parents feel guilty about their decision. Irrespective of the parents' attitude to vaccination the nurses show understanding that the parents want the best for their child. The nurses let the parents talk about their views and are careful not to question the parents' decision.

"It is very difficult to reach someone if one is guilt-tripping them. I would be very upset if someone I met questioned my decision when all I want is for the child to be in good health, which is what all parents want” (I 4).

The nurses are careful to leave room for parents who are hesitant to vaccination. They adopt an open and understanding demeanour providing parents with time to think about their decision whether or not to vaccinate their child. By giving the parents time for their decision the nurses show that they take the parents' concerns and hesitation seriously.

"So then I do not vaccinate that time. Instead we only talk about it and I encourage them to go home and think about it. And I say: if you want to vaccinate tomorrow, you just call me; if not, we can decide another appointment a bit further on to talk it over again” (I 7).

\subsubsection{Creating a relationship}

The nurses stated that it is imperative to create a good relationship in order to work with the parents in the course of their numerous visits to the child health centre. By actively listening the nurses can increase the likelihood of achieving a good relationship with the parents based on mutual trust.

"A lot depends on the relationship with the parents so I do not insist. If they have said no, I do not go on about it. At the three-month point I always raise the issue. At the five-month point I don't say much about it...At one year I ask again...but I only mention it and do not enter into any lengthy discussion about it” (I 3).

The nurses create a good relationship with the parents by being accessible. Their accessibility takes the form of continuous contact with the parents during their child's health centre monitoring period. The nurses mentioned the child's health check-ups as occasions for raising the question of vaccination to see whether or not the parents have changed their minds.

"The advantage of the child health centre system is that one meets the parents all the time so one can sow seeds as one goes along and explore if they have started to think differently” (I 8).

\subsubsection{Inspiring trust}

The nurses stated that the personal chemistry must be good for the meeting to inspire a sense of safety and trust. If the personal chemistry is not good nurses find it difficult to reach the parents and to get them to open up about their thoughts and concerns. Furthermore, the nurses believed that it is important to take the parents' doubts very seriously. By finding out why parents are worried nurses can take appropriate action and discuss the matter effectively. Nurses strive to discover what the parents need to know more about to dispel their concerns and inspire safety and trust.

"I think it is good they are worried because one should take care of one's children and give them the very best one can. So I ask what they are worried about. What do they want to know more about to feel less worried and feel safe about the matter" (I 7).

It is important parents feel safe with the nurses and trust them in discussions about child vaccinations and their doubts. The nurses believed that parents feel a sense of continuity and safety when they are allowed to meet with the same nurse. Nurses further increase the parents' sense of trust by advancing slowly and not pushing them for a decision.

"There are a lot of talks...One has to convey the message without persuading...because one does not want to do it that way. I think we should all agree so that it feels safe and good to vaccinate. It should feel safe and good and they should trust what we are doing” (I 10). 


\subsection{Being a discussion partner}

The nurses stated that it is important to be a discussion partner when meeting parents who are hesitant to child vaccinations. It is important to invite parents to talks. By getting to know the family and its background it becomes easier for the nurse to involve the parents in the discussion. Getting to know and encouraging participation are important strategies for being a good discussion partner in the meeting with parents.

\subsubsection{Getting to know}

As parents have different needs and resources, the nurses stated it is important to discover why the parents are hesitant about vaccinating their child. By getting to know the parents the nurse can understand their concerns more easily.

"As I interpret it as an anxiety it is easy to deal with it as such. One asks what concerns them specifically and then one deals with the items that surface, such as autism and mercury... One must find what worries them” (I 4).

The nurses stated that it is important to analyse the parents' doubts and knowledge about vaccines. Upon this basis the nurse can approach the matter and consider the parents' situation, fine-tune her approach to the specific discussion, and get to know the parents.

"I ask what they know, from where they have obtained their information, what they are concerned about and afraid of. I ask what their views are on the matter” (I 10).

\subsubsection{Encouraging participation}

All the nurses stated that participation is something one should prioritise in the discussions about vaccination. This is achieved by inviting parents into the talk about vaccination and being attentive to their opinions. One approach for achieving this is to let parents reinitiate the issue of vaccinations on their own terms.

"I usually raise the issue again but sometimes the parents say that they do not want to discuss the matter further. I then reply that I’ll let them initiate any further talk about it if they so wish...on their terms” (I 11).

Another strategy for involving the parents in the decision is to individualise the vaccination programme according to their wishes. One way of accommodating the parents is to offer separate vaccine doses.

“... and then one may have someone who does not want to have all the vaccines. I then present what can be given in separate doses, like tetanus and diphtheria, things I feel they absolute should take ... and many parents accept that” (I 3).

The nurses stated that is important to underline for the parents that it is they who decide, that the decision whether or not to vaccinate is theirs. Nurses are careful to ensure that parents are aware of the implications of vaccination.

"I am really quite clear about telling the parents that it is their decision, that they decide what the child should have, that it is important to check what one is giving the child, what it is one is injecting, and that one should have knowledge about it and not just inject something without knowing what it is all about” (I 3).

An open dialogue between nurse and parents is important to achieve a good discussion about vaccination. The hallmark of an open dialogue is the willingness to listen to the parents and to invite them to the talk, while ensuring a clear message.

"It is important they feel listened to and respected, that we are not trying to persuade them, because we want to achieve a dialogue about the issue” (I 5). 


\subsection{Providing knowledge}

The nurses stated that it is important they counter ignorance and misunderstanding about the childhood vaccination programme. The provision of information, advice and guidance are strategies used in the meeting with vaccine-hesitant parents. They help nurses convey knowledge to parents about the link between diseases and vaccinations.

\subsubsection{Providing information}

The nurses stated that parents are unaware of the nature of many of the diseases against which children are vaccinated because these diseases are no longer as prevalent as they once were. Being knowledgeable about the diseases and vaccines is therefore especially important. Nurses are careful to provide parents with information about the link between vaccinations and diseases and use concrete examples.

"... she had no idea that tetanus is found in soil, she thought tetanus was contagious, and was surprised to hear that it is enough the child falls and is scratched by a stick or nail to contract tetanus” (I 6).

The MMR vaccine is the one parents are most doubtful about as a result of studies linking it to autism. In this case, nurses use scientific evidence to show there is no evidence of a link between autism and the MMR vaccine.

"The good thing today is that it has now been scientifically proven that that article was not reliable, it is incorrect, which is something we can use; but many react against the vaccine” (I 3).

Nurses sometimes have to deal with situations where parents hesitate about vaccinating their child due to the influence of friends and relatives. In such situations it is important to clearly explain the difference between vaccinations today and in the past.

"If someone says: Yes, but my grandmother was vaccinated and became very sick, one simply explains that vaccines were not as clean in those days. Today they are much cleaner and one does not get side effects and so on. We have come much further and they agree with that” (I 7).

\subsubsection{Providing advice}

When nurses do not have enough knowledge, or find it difficult to explain the value of vaccines, when meeting vaccine-hesitant parents they encourage them to discuss the matter with a paediatrician.

“ $\ldots$ and then I always give the paediatrician’s phone number to those who are against. So then they can call and talk to him if they want to. After all, it is the parents who decide, I cannot decide” (I 3).

It is always important parents feel they have received all the information needed before taking their decision. Nurses therefore inform parents of the possibility of calling a paediatrician irrespective of the existence of doubt or uncertainty. This offer is always made.

"If they are really doubtful they are offered a visit to the paediatrician so they know they have received the right information and really know what they are saying no to" (I 9).

\subsubsection{Providing guidance}

The nurses stated that they often note that in today's connected society parents use multiple channels for obtaining information. Nurses try to find out where parents obtain their information and strive to steer them in the right direction by referring parents to reliable sources of information about the subject.

“... and I always refer the parents to the web pages of the National Board of Health and Welfare and the Public Health Agency where they can read more” (I 3). 
Nurses also come across parents who seem lost in their search for information. In this case nurses feel their guiding role to be particularly important and challenging.

“...some parents have read so much they are completely lost because of all the different information” (I 5).

In this case, nurses try to focus the discussion on the positive elements in the parents' reasoning about child vaccinations and try to make them consider the issue from new angles. In this way, the guidance is individualised in accordance with the parents' situation and desires.

\section{Discussion}

\subsection{Being supportive}

The results show that the supporting strategy encompasses the nurse being understanding, creating a relationship and inspiring trust. Nurses are careful to adopt an open and understanding demeanour towards the parents and to give them time to think through their decision. Previous research has also found that parents should be given space to think through their decision and that one should not pressure them ${ }^{[24]}$. This strategy also includes keeping the door open for the vaccination decision by reminding the parents that they can contact the nurse whenever they want.

Several studies ${ }^{[24,30]}$ describe the importance of the nurse accepting and respecting the parents' decision and not crossing the border between discussing and arguing the matter. This corresponds well with the results of this study, which found that nurses show understanding by listening to and respecting the parents' opinions and decision.

The results show that parents are encouraged to discuss their concerns and doubts about vaccinating their child. By having an open and understanding dialogue with the parents, without judging them, nurses show understanding for the parents' decision to protect their child. A sense of satisfaction with the vaccination decision can have significant domino effects and increase the likelihood of parents returning with their child for subsequent vaccine doses and of completing the childhood vaccination programme ${ }^{[24]}$.

This study found that nurses believe it is important to be able to create a good relationship in order to continue working together with the parents. Recame ${ }^{[16]}$ believes that the nurse should be a link between the parents and their doubts. A good relationship between nurse and parents has been found to affect the vaccination decision ${ }^{[31]}$. Nurses who treat parents as individuals and listen to their questions, and who are empathetic towards their concerns, find it easier to create a good and lasting relationship ${ }^{[24]}$. Providing support to the parents in an emotional period of their lives is therefore an important strategy that nurses can use ${ }^{[23]}$.

The nurses in this study noted that they had the possibility to raise the issue of vaccinations several times during their relationship and continuous contact with the parents throughout their child's health centre monitoring period. Creating a relationship and maintaining continuous contact with parents means adopting a family-centred attitude. A family-centred attitude includes having a professional relationship where the nurse over time increases the parents' sense of safety ${ }^{[20]}$. The value of this approach is confirmed in Diekema's ${ }^{[13]}$ as well as Harris, Hughbanks-Wheaton, Johnston and Kubin's ${ }^{[32]}$ studies. By adopting this strategy nurses may succeed in making parents reconsider a decision not to vaccinate.

By advancing slowly and not pressing parents for a decision, the nurses in the study believed that the parents' confidence in them was increased. A trust-inspiring nurse, according to Benin, Wiseler-Scher, Colson, Shapiro and Holmboe ${ }^{[3]}$, spends a lot of time with parents, discusses vaccines, and offers individualised help according to the parents' needs. Trust is described as a cornerstone in the relationship between parents and nurse. The trust between the parties is not created over night, it develops slowly over time ${ }^{[22]}$. It has been shown that parents who are hesitant to vaccines are often suspicious 
against government and believe information on vaccine side effects is kept from the general public ${ }^{[7]}$. The nurses in this study strove to discover why parents were worried about vaccines and what was needed to dispel their concerns. Dy and Purnell ${ }^{[33]}$ as well as Hill and Cox ${ }^{[31]}$ believe that trust is created when the nurse considers the family's well-being, is knowledgeable, and sees the family as a whole. Seeing the family as a whole means adopting a family-centred attitude where the nurse bases her work on and uses the family's resources and knowledge ${ }^{[20]}$. In this way the nurse can make parents feel more trusting towards her and instil a greater sense of safety in terms of childhood vaccinations.

\subsection{Being a discussion partner}

By getting to know the parents, exploring their knowledge, opinions and situation, nurses can plan the discussion with them and make it more successful. According to Austvoll-Dahlgren and Helseth ${ }^{[11]}$ the information provided by the nurse should be balanced, describing both advantages and disadvantages, and be concluded with a qualified recommendation, while providing the parents with room to express themselves and take time for their decision. Previous studies have shown the importance of the nurse exploring both the parents' knowledge about vaccinations and the reasons they are hesitant. In order to get to know the parents, nurses should obtain information about their background, for instance their religious, cultural and personal characteristics, as it may influence their decision ${ }^{[12,34]}$. Both Harris et al. ${ }^{[32]}$ and Jansson et al. ${ }^{[23]}$ state that the nurse can obtain a comprehensive view of the family's life situation by actively involving the parents in the discussion. Being a discussion partner with the parents is therefore an important strategy for the nurse to successfully get to know the family and adopt a family-centred attitude.

All the nurses encouraged participation in their vaccine discussions with parents. To make the parents feel involved in the vaccination decision, the nurses offered to adapt the vaccination programme to the parents' wishes, to individualise the programme, for instance by offering vaccines in separate doses. Diekema ${ }^{[12]}$ writes about this approach and argues that it makes parents feel more involved and more positive towards vaccination.

The nurses in this study wanted the parents to be involved and achieved this by inviting the parents into the discussion about vaccines and by actively listening to understand their opinions. Being a discussion partner is a strategy used by nurses to get to know parents and make them feel involved in the meeting. This offers the nurse the determining role for creating trust and involvement when dealing with vaccine doubts and hesitation. An earlier study confirms the importance of nurses involving parents and respecting their opinions ${ }^{[35]}$.

\subsection{Providing knowledge}

Confirming the result of earlier studies ${ }^{[3,36-38]}$, the nurses in this study believed that parents had poor knowledge of the vaccines offered and of the diseases they prevent. To remedy this shortcoming, the nurses used the strategy of providing knowledge to parents during the meeting. The nurses always informed the parents of the vaccines and the diseases prevented and then followed up the subject at the next visit. It also emerged that the nurses used concrete examples to underline the value of vaccinations, which is something Ball et al. ${ }^{[34]}$ describe in their study. By using concrete examples to clarify the risks of the diseases, and by guiding the parents towards expert sources of information about vaccines and the childhood vaccination programme, nurses can provide vaccine-hesitant parents with a new perspective on vaccines and perhaps change the parents' opinion about vaccination.

There were situations where the nurses in this study felt they were inadequate in the meeting with vaccine-hesitant parents. The nurses stated that in such situations it was important for them to feel that the parents had received the information they needed, and the nurses therefore suggested that the parents contact a paediatrician. This strategy is confirmed by Ball et al. ${ }^{[31]}$ who describe how nurses refer to more knowledgeable health care staff when they do not possess the knowledge needed to answer the parents' questions.

This study found that nurses believed that the parents' decision whether or not to vaccinate their child can be influenced by, for instance, mass media, Internet sources and friends. Several studies note that the number of information channels 
available in society has increased enormously and that parents may find it difficult to determine which sources are reliable ${ }^{[36-40]}$. In situations where the parents seem to have been influenced the nurses use their guiding role. They first identify the parents' source of information and then refer to scientific evidence and expert sources that can clarify and explain the matter to the parents, for instance the supposed link between autism and the MMR vaccine. A study by Dannetun, Tegnell, Hermansson and Giesecke ${ }^{[41]}$ describes how well-informed and updated nurses can provide parents with individualised information based on research and science so they may come to the right decision. The issue is promoting the parents' trust in the nurse's scientific knowledge. The nurse's trustworthiness has been found to be a determining factor when parents decide to vaccinate their children ${ }^{[24]}$.

The nurses in this study also described meeting parents who seemed more or less lost in their search for information about child vaccinations. In this case the nurses' guiding role becomes especially challenging and important. By referring to reliable sources of information about the subject nurses can steer the parents in the right direction. This confirms the conclusion of a previous study that this strategy is useful when dealing with parents who are hesitant to child vaccinations ${ }^{[123]}$. The final decision lies with the parents, but the nurse must provide the information needed to fully consider the issue of vaccination ${ }^{[25]}$. This approach confirms the result of this study that nurses always try to find out what parents know and from where they have obtained their information.

\section{Study limitations}

The authors' preunderstanding and experience as nurses can be a strength as they are familiar with the healthcare environment. This experience can be useful when understanding and interpreting the responding nurses' descriptions of the meeting with parents who are hesitant to child vaccinations. Conversely, the authors' experiences as nurses may be a weakness as it may entail that the familiar and nuances are overlooked. To offset this potential shortcoming, and to increase the study's reliability, the authors have striven to maintain a critical attitude towards their preunderstanding during both the interviews and the analysis thereof. Furthermore, during the interview reading and analysis process, the authors first read and analysed each interview separately, then repeated the process together, and each step of the process was reviewed to take into account alternative interpretations. To limit the risk of bias, the researchers were constantly aware that in the context of qualitative research the researcher participates in the interview and therefore may influence the interview's content ${ }^{[28]}$.

As the purpose of qualitative content analysis is to highlight the individual's experience, and not to generalise, the study population was limited to twelve respondents. The fact that there are not many men working in child health centres explains why the study population contained women only, which may be seen as a limitation.

\section{Practical implications and further research}

In the meeting with parents who are hesitant to child vaccinations nurses use their ability to inspire trust and create a participatory relationship with parents. The strategies of being supportive, being a discussion partner and providing knowledge could be used in similar situations between parents and child health centre nurses. The strategies identified in this study could be used to draft an action plan for nurses dealing with vaccine-hesitant parents. The basis for such an action plan could be a family-centred attitude encompassing the following strategies:

- Use the family's resources and knowledge to create understanding, a relationship, and trust in the child vaccination decision-making process

- Continuous meetings between the family and the same nurse throughout the child health centre monitoring period

- Open dialogue with the parents and active listening to their questions and concerns in order to get to know them and involve them in the meeting with the nurse 
- Interprofessional cooperation with regular meetings between nurse and paediatrician

- Training to increase the nurses' skills when new vaccines are introduced or the vaccination programme is changed

- Skills in providing information about and guiding parents among publicly available information channels (mass media and internet).

The first three of these six strategies confirm the findings of earlier research. The last three strategies constitute this study's particular contribution to the field.

\section{Conclusion}

This study focused on the meeting between child health centre nurses and parents who are hesitant to child vaccinations and it identified various strategies used by nurses. It is crucial that nurses take time to get to know the parents and provide space for listening to and understanding the parents' hesitations. Furthermore, it is important to approach vaccine-hesitant parents with understanding, to establish a good relationship with them, and to inspire trust and try to make them actively involved in the decision-making concerning their child's vaccination. From a societal point of view it is imperative to work towards good vaccination coverage by means of knowledge and training. However, in the meeting with vaccine-hesitant parents it is of great importance to not guilt-trip those who do not want to vaccinate their child.

\section{Funding}

The authors received no financial support for the research, authorship, and/or publication of this article.

\section{Conflict of interest}

The authors declare that they have no conflict of interest.

\section{Acknowledgments}

The authors thank Patrick Reis for his valuable writing, translation and proofreading assistance for this article. The authors also thank the respondents for sharing their experiences.

\section{References}

[1] Socialstyrelsen. Vaccination av barn. Det svenska vaccinationsprogrammet. En kunskapsöversikt för hälsovårdspersonal. Socialstyrelsen. 2008. Available from: http://www.socialstyrelsen.se/publikationer2008/2008-126-9

[2] Poland GA. MMR vaccine and autism: vaccine nihilism and postmodern science. Mayo Clinic Proceedings. 2011 September; 86(9): 869-871. PMid:21878599 http://dx.doi.org/10.4065/mcp.2011.0467

[3] Benin AL, Wisler-Scher DJ, Colson E, Shapiro ED, Holmboe ES. Qualitative analysis of mothers’ decision-making about vaccines for infants: the importance of trust. Pediatrics. 2006 May 3; 117(5): 1532-1541. PMid:16651306

http://dx.doi.org/10.1542/peds.2005-1728

[4] Simone B, Carrillo-Santisteve P, Lopalco P. Healthcare workers' role in keeping MMR vaccination uptake high in Europe: a review of evidence. Euro Surveillance. 2012 June 28; 17(26). Available from: http://eurosurveillance.org/Viewarticle.aspx?Articleld=20206

[5] Gust DA, Kennedy A, Shui I, Smith PJ, Norwak G, Pickering LK. Parents’ attitudes towards immunizations and healthcare providers: The role of information. American Journal of Preventive Medicine. 2005 August; 29(2): 105-112. PMid:16005806 http://dx.doi.org/10.1016/j.amepre.2005.04.010

[6] Skea Z, Entwistle V, Watt I, Russell E. 'Avoiding harm to others' considerations in relation to parental measles, mumps and rubella (MMR) vaccination discussions - an analysis of an online chat forum. Social Science \& Medicine. 2008 November; 67(9): 1382-1390. 
[7] Samuelsson K, Blennow M. Föräldrar har tillit till barnvaccinationer- Men samtidigt brister deras förtroende för det medicinska etablissemanget visar en kvalitativ attitydstudie. Läkartidningen. 2003; 100(40): 3132-3135. PMid:14579664

[8] Opel DJ, Marcuse EK. Window or Mirrors: Social Networks’ Role in Immunization Decisions. Pediatrics. 2013 April 15; 5(131): 1619-1620. PMid:23589807 http://dx.doi.org/10.1542/peds.2013-0531

[9] Ekholm L. Rikshandboken Barnhälsovård. Hur fungerar vaccinationer. Rikshandboken Barnhälsovård. 2013a. Available from: http://www.rikshandboken-bhv.se/Texter/Nar-hur-och-varfor/Hur-fungerar-vaccinationer/

[10] Gross L. A broken trust: lessons from the vaccine-Autism Wars. PLoS Biology. 2009 May 26; 5(7): e1000114. PMid:19478850 http://dx.doi.org/10.1371/journal.pbio.1000114

[11] Austvoll-Dahlgren A, Helseth S. What informs parents' decision-making about childhood vaccinations? Journal of Advanced Nursing. 2010 August 16; 66(11): 2421-2430. PMid:20722796 http://dx.doi.org/10.1111/j.1365-2648.2010.05403.x

[12] Diekema DS. Responding to parental refusals of immunization of children. Pediatrics. 2005 May 1; 5(115): $1428-1431$. http://dx.doi.org/10.1542/peds.2005-0316

[13] Lindberg A. Misstron mot vaccinationer måste bemötas med respekt. Läkartidningen. 2013; 16(110): 822-824.

[14] Nicholson MS, Leask J. Lessons from an online debate about measles-mumps-rubella (MMR) immunization. Vaccine. 2012 May 28; 30(25): 3806-3812. PMid:22063388 http://dx.doi.org/10.1016/j.vaccine.2011.10.072

[15] Wakefield A, Murch S, Anthony A, Linnell J, Casson DM, Malik M, Berelowitz M, Dhillon AP, Thomson MA, Harvey P, Valentine A, Davies SE, Walker-Smith JA. Ileal-lymphoid-nodular hyperplasia, non-specific colitis, and pervasive developmental disorder in children. Lancet. 1998 February 28; 351(9103): 637-641. http://dx.doi.org/10.1016/S0140-6736(97)11096-0

[16] Recame MA. The immunization-autism myth debunked. International Journal of Childbirth Education. 2012 October 1; 27(4): 76-78.

[17] Andre FE, Booy R, Bock HL, Clemens J, Datta SK, John TJ, Lee BW, Lolekha S, Peltola H, Ruf TA, Santosham M, Schmitt HJ. Vaccination greatly reduces disease, disability, death and inequity worldwide. Bulletin of the World Health Organization 86.2008 November 27; 86: 140-146.

[18] Nationella nätverket för Vårdutvecklare/Barnhälsovårdssamordnare. Nationell målbeskrivning för sjukskötersketjänstgöring inom Barnhälsovården. Malmö: Utvecklingsenheten för Barnhälsovård/Skåne sydväst. 2007.

[19] Aarthun A, Akerjordet K. Parent participation in decision-making in health-care services for children: an integrative review. Journal of Nursing Management. 2014 March; 22(2): 177-191. http://dx.doi.org/10.1111/j.1365-2834.2012.01457.x

[20] Arango P. Family-centered care. Academic Pediatrics. 2011; 11: 97-99. PMid:21282085 http://dx.doi.org/10.1016/j.acap.2010.12.004

[21] Magnusson M, Blennow M, Hagelin E, Sundelin C. Barnhälsovård - att främja barns hälsa. Stockholm: Liber. 2009.

[22] Lynns-McHale D, Deatrick J. Trust between family and health care provider. Journal of Family Nursing. 2000 August; 6(3): 210-230. http://dx.doi.org/10.1177/107484070000600302

[23] Jansson AK, Petersson K, Udén G. Nurses' first encounters with parents of new-born children -- public health nurses’ views of a good meeting. Journal of Clinical Nursing. 2001 December 21; 10: 140-151. http://dx.doi.org/10.1046/j.1365-2702.2001.00456.x

[24] Donovan H, Bedford H. Talking with parents about immunisation. Primary Health Care. 2013 January 29; 23(4): 16-20. http://dx.doi.org/10.7748/phc2013.05.23.4.16.e741

[25] Ekholm L. Rikshandboken Barnhälsovård. Tveksamma föräldrar. Rikshandboken Barnhälsovård. 2013b. Available from: http://www.rikshandboken-bhv.se/Texter/Nar-hur-och-varfor/Hur-fungerar-vaccinationer

[26] SOSFS. Socialstyrelsens föreskrifter om vaccination av barn. Stockholm: Socialstyrelsen. 2006:22.

[27] Polit DF, Beck HT. Nursing research. Generating and assessing evidence for nursing practice. Philadelphia: Wolters Kluwer/Lippincott Williams \& Wilkins. 2012.

[28] Graneheim UH, Lundman B. Qualitative content analysis in nursing research: concepts, procedures and measures to achieve trustworthiness. Nurse Education Today. 2004 March 31; 24: 105-112. PMid:14769454 http://dx.doi.org/10.1016/j.nedt.2003.10.001

[29] Vetenskapsrådet. Forskningsetiska principer inom humanistisk-samhällsvetenskaplig forskning. Stockholm: Elanders Gotab. 2002. Available from: http://www.codex.vr.se/texts/HSFR.pdf

[30] Tenrreiro KN. Time-efficient strategies to ensure vaccine risk/benefit communication. Journal of Pediatric Nursing. 2005; 20(6): 469-476. http://dx.doi.org/10.1016/j.pedn.2005.06.012

[31] Hill MC, Cox CL. Influencing factors in MMR immunisation decision making. British Journal of Nursing. 2013 October 22; 15(22): 893-898. PMid:24005660 http://dx.doi.org/10.12968/bjon.2013.22.15.893

[32] Harris KM, Hughbanks-Wheaton DK, Johnston R, Kubin L. Parental refusal or delay of childhood immunization: Implications for nursing and health education. Teaching and Learning in Nursing. 2007 January; 2(1): 126-132. http://dx.doi.org/10.1016/j.teln.2007.07.005 
[33] Dy SM, Purnell TS. Key Concepts relevant to quality of complex and shared decision-making in health care: A literature review. Social Science \& Medicine. 2012 February; 74(4): 582-587. PMid:22236643 http://dx.doi.org/10.1016/j.socscimed.2011.11.015

[34] Ball LK, Evans G, Bostrom A. Risky business: challenges in vaccine risk communication. Pediatrics. 1998 March 1; 3(101): 453-458. http://dx.doi.org/10.1542/peds.101.3.453

[35] Eldh AC, Ekman I, Ehnfors M. A comparison of the concept of patient participation and patients' descriptions as related to healthcare definitions. International Journal of Nursing Terminologies and Classifications. 2010 January-March; 1(21): $21-32$. PMid:20132355 http://dx.doi.org/10.1111/j.1744-618X.2009.01141.X

[36] Chesser A, Paschal A, Hart T, Jones J, Williams KS, Ahlers-Schmidt CR. Communication practices for pediatric immunization information: physician perceptions of parent health literacy skills. Clinical Pediatrics. 2012 May; 51(5): 504-506. PMid:21525085 http://dx.doi.org/10.1177/0009922810396548

[37] Hilton S, Hunt K, Petticrew M. Gaps in parental understandings and experiences of vaccine-preventable diseases: a qualitative study. Child: care, health and development. 2006 June 16; 33(2): 170-179. PMid:17291321 http://dx.doi.org/10.1111/j.1365-2214.2006.00647.x

[38] Omer SB, Salmon DA, Orenstein WA, de Hart P, Halsey N. Vaccine refusal, mandatory immunization, and the risks of vaccine-preventable diseases. The New England Journal of Medicine. 2009 May 7; 360(19): 1981-1988. PMid:19420367 http://dx.doi.org/10.1056/NEJMsa0806477

[39] Healy MC, Pickering LK. How to communicate with vaccine-hesitant parents. Pediatrics. 2011 April 18; 127(1): 127-133. PMid:21502238 http://dx.doi.org/10.1542/peds.2010-1722S

[40] Leask J, Kinnersley P, Jackson C, Cheater F, Bedford H, Rowles G. Communicating with parents about vaccination: a framework for health professionals. Pediatrics. 2012 September 21; 12(154). PMid:22998654

[41] Dannetun E, Tegnell A, Hermansson G, Giesecke J. Parents’ reported reasons for avoiding MMR vaccination. Scandinavian Journal of Primary Health Care. 2005; 23(3): 149-153. PMid:16162466 http://dx.doi.org/10.1080/02813430510031306 